\title{
APOSTILA DE TREINAMENTO NA EXTENSÃO RURAL: ESPAÇO DE TENSÃO ENTRE O DISCURSO DA APLICACÃO DA CIÊNCIA E O DA EXPERIÊNCIA PRÁTICA NO CAMPO
}

Eric Duarte Ferreira*

\begin{abstract}
Resumo: O objetivo deste trabalho é analisar o jogo entre a produção e a aplicação de saber em um corpus composto por apostilas de treinamento utilizadas em cursos de Extensão Rural sobre armazenamento de grãos. Partimos da seguinte questão central: como um saber do campo científico é deslocado para o campo da utilização (pedagógico)? Metodologicamente, tomamos esses campos como dois planos que comportam modos distintos de produção de enunciados, de acordo com o que Foucault (1969, 1963) desenvolve a respeito das modalidades enunciativas. Acreditamos que se configura uma tensão no plano pedagógico (plano do dizer) entre os conhecimentos científicos praticados fora do domínio da ciência (na Extensão Rural) e os conhecimentos ditos "tradicionais" em armazenamento de grãos. Os resultados apontam que o instrumento apostila de treinamento funciona como outra modalidade de enunciação do saber científico que apaga a tensão entre os modos de produção de saber científico e "tradicional".
\end{abstract}

Palavras-chave: modalidade enunciativa; circulação de saber; discurso; apostila.

\footnotetext{
* Mestre em Lingüística pela Universidade Federal de Santa Catarina. Doutorando em Lingüística Análise de Discurso - na mesma universidade. E-mail: <ericletras@yahoo.com.br>.
} 


\section{INTRODUÇÃO}

Podemos dizer que o ensino na extensão rural se dá como prática na relação com o científico, com o acadêmico, pois um saber produzido no âmbito científico se apresenta como objeto do discurso pedagógico praticado na extensão rural. $O$ saber é aqui entendido como "um conjunto de elementos, formados de maneira regular por uma prática discursiva e indispensáveis à constituição de uma ciência, apesar de não se destinarem necessariamente a lhe dar lugar", de acordo com o que define Foucault (1969, p. 204). No imaginário do agricultor que se torna um aprendiz ${ }^{1}$, esse objeto se apresenta como algo que se deve conhecer.

Nesse jogo que se apresenta entre produção e aplicação de saber, uma questão central surge e marca o início deste trabalho, estendendo-se como uma inquietação que o norteia: como um saber que é do campo da produção é deslocado para o campo da utilização? A partir desse questionamento, traçamos o objetivo central desta pesquisa, que consiste em analisar os modos de circulação de saber; precisamente, analisar a maneira pela qual um saber circula de um plano de enunciação a outro plano de enunciação, ou seja, o modo pelo qual ele circula do científico para a aplicação - o pedagógico ${ }^{2}$.

Escolhemos o saber a respeito do armazenamento de grãos para concretizar a análise. No âmbito desse saber, armazenar é reduzir ao mínimo possível os fatores que prejudicam a "saúde" dos alimentos, prolongando ao máximo, através de um conjunto de procedimentos e técnicas, seu tempo útil de consumo. Entretanto, o que interessa à pesquisa é a forma discursiva que toma esse saber conforme ele é deslocado de uma modalidade de enunciação a outra, e não o seu conteúdo.

É importante ressaltar que os cursos de extensão rural que abrangem o tema do armazenamento de grãos são direcionados para produtores rurais que já possuem um conhecimento sobre o

\footnotetext{
${ }^{1}$ Preferimos adotar o nome "aprendiz" em vez de "aluno", por acreditarmos que na extensão rural, nos termos citados, trata-se de educação não-formal.

2 Este texto é uma síntese de minha dissertação de mestrado, defendida em fevereiro de 2007 no Programa de Pós-Graduação em Lingüística da Universidade Federal de Santa Catarina (cf. FERREIRA, 2007), sob orientação do Prof. Dr. Pedro de Souza.
} 
armazenamento, isto é, ao chegarem aos cursos de extensão, esses sujeitos são detentores de um saber sobre o armazenamento que advém da experiência prática no campo, atravessada por uma "tradição"3 em armazenamento - "saberes passados de geração a geração". Assim como dissemos que os planos científico e pedagógico possuem modos diferentes de produção de enunciados, afirmamos também, com base na teoria foucaultiana, que o plano da experiência prática possui um modo discursivo de produção de saber distinto dos demais.

Dessa forma, podemos dizer que há uma tensão no plano da aplicação - o pedagógico - entre duas instâncias produtoras de saber. Em outras palavras, há uma tensão entre a instância de produção de saber no discurso científico e a instância de produção de saber na experiência prática. E, como sabemos, em um determinado momento, e por meio do discurso pedagógico, o discurso científico predomina sobre o modo de produção de saber na experiência prática, apagando a tensão: o agricultor utiliza esse saber científico na sua prática de armazenagem.

A função do pedagógico parece ser esta: apagar a tensão entre esses dois planos de enunciação. $\mathrm{E}$ o faz instrumentalizado pelas cartilhas, apostilas, etc., utilizadas nas aulas dos cursos dados aos produtores rurais nas atividades de extensão. Chegamos, assim, à hipótese levantada neste trabalho: a de que esse instrumental utilizado no pedagógico (na prática da extensão rural) funciona como outra modalidade de enunciação do saber científico, apagando a tensão entre os modos de produção de saber científico e tradicional.

Para alcançarmos o objetivo proposto e realizar a checagem da hipótese apresentada, o corpus de análise será constituído, no âmbito do pedagógico, por apostilas de treinamento do Curso em Armazenagem de Grãos promovido pelo Centro de Treinamento em Armazenagem

\footnotetext{
3 Sabemos que a noção de tradição é problemática por formar um conjunto, uma continuidade que remete a uma origem e à não dispersão da história. Segundo Foucault (1969, p. 23), essa noção não tem uma estrutura conceitual muito rigorosa, mas sua função é precisa: "ela visa a dar uma importância temporal singular a um conjunto de fenômenos, ao mesmo tempo sucessivos e idênticos (ou pelo menos análogos)". Portanto, "tradição" ou "tradicional" são utilizados no decorrer do trabalho em referência àquilo que, de acordo com o corpus, é considerado como tradição: um conjunto de saberes que são da ordem do não científico, do senso comum em armazenamento (e que pode ser transmitido).
} 
68

(CENTREINAR). No âmbito do científico, acrescentaremos ao corpus os artigos científicos a partir dos quais foram elaboradas as apostilas ${ }^{4}$.

$\mathrm{Na}$ instância em que circula o saber produzido no plano científico a respeito do armazenamento de grãos, o pedagógico - que é apenas uma dentre as diversas instâncias pelas quais circula um saber em nossa sociedade -, a análise diz respeito ao estabelecimento das relações do sujeito que enuncia no discurso pedagógico e no discurso científico, também ao modo de inserção do sujeito falante em um plano de enunciação e em outro, o que define, assim, diferentes maneiras de produção de enunciados. Por isso, a noção de modalidade enunciativa desenvolvida por Foucault $(1969,1963)$ alinhará a análise.

\section{O CORPUS}

As apostilas que compõem o corpus foram selecionadas por meio de um recorte feito no conjunto de "materiais didáticos" utilizados no Curso em Armazenagem de Grãos promovido pelo Centro Nacional de Treinamento em Armazenagem, na região de Marau, no Rio Grande do Sul, de 22 a 25 de junho de 2004 (CENTREINAR, 2004). Das treze apostilas utilizadas nesse curso, nos interessam quatro, consideradas pelos extensionistas como "centrais", a saber: Pragas dos grãos armazenados e métodos de controle; Principais fungos de grãos armazenados, micotoxinas e seus efeitos; Aeração de grãos; Segurança do trabalho em unidades armaz̧enadoras.

Devido à forma pela qual o CENTREINAR está organizado, alguns professores de ensino superior da UFV (Universidade Federal de Viçosa - MG) desempenham uma função pivô nesse centro de treinamento. Os docentes que compõem o quadro de instrutores dessa

\footnotetext{
${ }^{4}$ Embora esse instrumental do curso em armazenamento de grãos tenha sido elaborado a partir de artigos científicos, não será tomado como espaço de vulgarização científica, porque acreditamos que há uma diferença entre vulgarização e "pedagogização". Essa diferença tem a ver com a prática. Sabemos que o pedagógico é o domínio próprio da utilização, da aplicação, porque tem o objetivo de treinar como utilizar o saber científico no quadro de determinadas práticas, como, neste caso, a prática do armazenamento de grãos. Entretanto, o modo de funcionamento de espaços de vulgarização científica é o de somente informar sobre um determinado saber em andamento no domínio da ciência, não envolvendo a utilização do saber em certas práticas, ou na modificação delas (para o desenvolvimento dessa diferenciação, cf. FERREIRA, 2007).
}

FERREIRA - Apostila de treinamento na... 
organização são pesquisadores da UFV. Este fato tem relação direta com o objetivo geral do centro de treinamento em armazenagem: aplicar os frutos das pesquisas (os saberes) realizadas na universidade nas salas de treinamento. Por causa disso, vemos que esses professores universitários desempenham um duplo papel, que envolve a produção e a aplicação de saber.

No tocante às apostilas que se apresentam como a aplicação de saberes produzidos no âmbito científico, é oportuno perguntarmos como se estabelece a forma dos enunciados do instrumental analisado. Que modalidade de enunciação adota esse sujeito que produz o saber na instância em que ele apresenta esse saber de modo pedagógico?

A fim de discutir as questões acima, dentro do propósito deste trabalho, julgamos necessário desenvolver teoricamente o conceito de modalidades enunciativas, proposto por Foucault.

\section{AS MODALIDADES ENUNCIATIVAS}

Em $A$ formação das modalidades enunciativas, da obra $A$ arqueologia do saber, Foucault $(1969)^{5}$ propõe que as diversas modalidades da enunciação estão associadas às relações do sujeito que enuncia. Para o teórico, os diferentes modos de produção de enunciados estão associados ao status, aos lugares institucionais, à situação, enfim, aos modos de inserção do sujeito falante. É na relação desses elementos, ou seja, no estabelecimento das relações do sujeito que enuncia, que a descrição das formas dos enunciados ou a descrição de suas modificações é possível.

Foucault utiliza o domínio da medicina para ilustrar sua argumentação a respeito de cada um dos elementos citados acima. Para a descrição da forma dos enunciados do discurso médico, o autor propõe que se responda a algumas questões para a definição desses elementos. Com relação ao primeiro deles, o status, o autor apresenta questões como: quem fala? Quem, no conjunto de todos os indivíduos-que-falam, está autorizado a ter esta espécie de linguagem? O status define a

\footnotetext{
5 As obras de Foucault que são fundamentais para este trabalho serão citadas pelo ano de sua primeira publicação (cf. Referências).
} 
personagem (o médico), de forma que a fala médica não pode vir de quem quer que seja, pois seu valor, sua eficácia, seus poderes terapêuticos e sua existência não podem ser dissociados dessa personagem.

Com relação aos lugares institucionais, é necessário que se respondam às seguintes questões: de que lugares institucionais procedem os discursos? De onde o sujeito obtém seu discurso?

No que diz respeito à situação, há de se responder às questões: quais as posições do sujeito frente aos diversos domínios ou grupos de objetos? É sujeito que questiona? É sujeito que observa? O sujeito utiliza intermediários instrumentais? Que posições o sujeito ocupa na rede de informações, no campo dos domínios teóricos e institucionais?

A argumentação construída a respeito das modalidades enunciativas, desenvolvidas por Foucault na obra de 1969, $A$ arqueologia do saber, liga-se às suas pesquisas realizadas anteriormente, que culminaram na edição do livro O nascimento da clínica, em 1963. Nesta obra, Foucault se ocupa da maneira pela qual se modificaram, no fim do século XVIII e início do XIX, as formas de enunciação do discurso médico.

Segundo Foucault (1963), não há continuidade entre os conhecimentos médicos da Idade Clássica - séculos XVII e XVIII - e a medicina clínica moderna. Há, ao contrário, uma ruptura. Entretanto, a clínica nasce não de rupturas semelhantes às que a medicina moderna apresenta, identificando sua origem na positividade, em um empirismo, cuja essência é a redescoberta dos valores absolutos do visível e o resoluto abandono dos antigos sistemas e de suas quimeras.

Para o autor, a medicina moderna deve ser tomada, então, como o resultado de uma mutação das relações do sujeito que enuncia no discurso médico. Essa transformação se operou ao nível da relação entre aquele que fala e aquilo de que se fala, mudando a estrutura da racionalidade do conhecimento médico e o domínio de sua experiência.

A medicina clássica, de caráter eminentemente classificatório, tem como objeto a doença considerada como essência abstrata, que se define pela estrutura visível - pela superfície -, e para conhecê-la deve-se subtrair o indivíduo com suas qualidades singulares, pois o doente atrapalha, compromete a classificação. 
Em contraposição, na medicina moderna, a doença se define pela relação com a profundidade: o olhar médico deve penetrar verticalmente o corpo doente e dar conta de sua singularidade, pois não existem essências das doenças: a doença é uma reação a uma causa irritante. Ela deixa de ser uma espécie natural, vista botanicamente. O hospital não é mais um local de assistência ao pobre e de preparação para a morte, pelo contrário, "torna-se um espaço privilegiado de exercício da medicina tanto do ponto de vista da cura quanto do ensino. Nele a saúde substitui a salvação" (Machado apud FOUCAULT, 2004).

\subsection{A pedagogia e os hospitais}

Refazendo a história das instituições em que se manifestaram os esforços de organização da experiência clínica, Foucault (1963, p. 62) se dá conta de dois fatos: i) "O exame dos casos, sua exposição detalhada, sua relação com uma explicação possível é uma tradição muito antiga na experiência médica; a organização da clínica não é, portanto, correlata à descoberta do fato individual na medicina"; ii) em um estágio anterior à clínica moderna, chamada de "protoclínica", "a necessidade de um ensino por meio da prática também era amplamente reconhecida: a visita aos hospitais pelos aprendizes de médico era uma prática aceita".

Entretanto, essa clínica primeira não pôde descobrir novos objetos, formar novos conceitos, enfim, inventar um novo conjunto de discursos e de práticas encontradas na clínica moderna, apesar de sua complexidade.

Diante dessas constatações, o autor passa a construir o que seria a resposta ao seguinte questionamento: se o exame de caso e seu estudo sucessivo e coletivo já eram realizados nos hospitais e o ensino do saber era efetuado por meio da prática (numa relação com o campo da aplicação dos conhecimentos teóricos), o que separaria, então, essa protoclínica da clínica moderna? A diferença fundamental entre essas clínicas está nas relações do sujeito que enuncia em cada uma delas: está nas posições de subjetividade, como aponta Foucault.

$\mathrm{Na}$ protoclínica, a clínica possui uma função eminentemente pedagógica. A configuração da relação do campo de saber com a prática é exclusivamente a da aplicação. É a maneira de apresentar o conhecimento da medicina classificatória aos aprendizes de médico, de 
forma que o doente sirva para exemplificar a doença. Não há efetivamente um exame nos hospitais, e sim a decifração da doença no doente. Este é uma forma de ilustrar uma verdade já adquirida, produzida em outro lugar. Portanto, a protoclínica não é um instrumento para descobrir uma verdade ainda desconhecida, ela é lugar de circulação de saber. Para Foucault, a protoclínica não constitui em si uma experiência, mas é o resultado, para o aprendiz, de uma experiência anterior. Em suma, nessa clínica primeira, o campo da aplicação do saber é limitado a dizer saberes, ou seja, nesse espaço somente se diz, não se produz saber.

Além disso, o autor afirma que, nessas condições, na relação mestre-discipulo que se configura na pedagogia realizada nos hospitais antes da mutação que reorganizou o saber médico, a clínica tinha uma direção apenas: "a que vai, de cima para baixo, do saber constituído à ignorância” (1963, p. 65).

Com a inserção da reforma nessa pedagogia realizada nos hospitais, Foucault mostra que ocorre uma transformação fundamental na organização do conhecimento médico e de sua prática: passa-se a produzir saber, ao invés de somente demonstrá-lo, o que afasta a protoclínica dessa clínica emergente. Por conseguinte, "a clínica recebe um campo de aplicação não mais limitado àquele em que se diz um saber, mas coextensivo àquele em que nasce, se experimenta e se realiza saber" (1963, p. 67). Essa nova pedagogia fará corpo com a totalidade da experiência médica, pois a nova clínica passa a ter uma dinâmica própria e pode, então, descobrir novos objetos, formar novos conceitos e, por um outro modo de enunciar, inventar um novo conjunto de discursos e práticas.

Esse novo posicionamento do sujeito na pedagogia realizada nos hospitais, que passa da demonstração à descoberta, vai reorganizar todo o conhecimento médico; enfim, vai mudar as formas de enunciação no discurso da clínica. É justamente este o ponto que gostaríamos de ressaltar no trabalho realizado por Foucault (1963) e que é de grande valia para esta pesquisa: a mutação que se operou nas relações do sujeito que enuncia e reformulou o próprio saber, expressa na mudança do discurso médico, que passa a falar por outras formas de dizer, numa nova linguagem, sobre outro domínio da experiência médica. Em cada um desses posicionamentos, do que demonstra e do que produz saber, estão 
implicadas distintas posições de sujeito e diferentes modalidades de enunciação.

\section{Apostila de treinamento: espaço de tensão}

Conforme dissemos, no caso que pretendemos analisar - o curso de extensão rural realizado em Marau/RS -, o sujeito agricultor já possui um conhecimento considerado, de acordo com o corpus, como "tradicional", sobre o que lhe será transmitido nas aulas de extensão rural. Esse saber advém da experiência prática no campo, que se constitui como um modo discursivo de produção de enunciados diferente do científico e do pedagógico. Além disso, assim como o plano científico, é produtora de saber. Uma verdade sobre o armazenamento é constituída na experiência prática de acordo com um determinado sistema de regras que é próprio desse campo.

Ora, se o sujeito agricultor detém esse saber do ponto de vista que o produz na experiência prática, que constitui a verdade em armazenamento, configura-se no plano pedagógico (plano do dizer) uma tensão entre duas instâncias produtoras de saber/verdade, entre a instância produtora de saber do científico e a instância produtora de saber da experiência prática.

Como nosso corpus se compõe de instrumentos do plano pedagógico - as apostilas de treinamento -, iremos, no decorrer de nossa análise, buscar nessa materialidade discursiva as marcas dessa tensão instaurada no discurso da aplicação da ciência, salientando que não nos interessam as marcas em si, mas seu funcionamento no discurso. É este funcionamento que procuraremos compreender e descrever.

\subsection{Os saberes científico e tradicional}

A apostila intitulada "Principais fungos de grãos armazenados, micotoxinas e seus efeitos" possui, na primeira página, uma parte nomeada "Introdução", onde se delineiam aspectos gerais e características sobre os fungos na forma de tópicos, como abaixo:

(1) os fungos são os principais microorganismos da microflora e se encontram mundialmente difundidos. 
(2) apresentam estruturas relativamente simples, dimensões microscópicas e grande capacidade de sobrevivência. (CENTREINAR, 2004, p. 1, grifos nossos) ${ }^{6}$

Em seguida, na mesma página, vemos se formar um alerta, direcionado ao agricultor que armazena sua produção de grãos, de que os fungos são um dos causadores da perda da qualidade dos grãos, e que esses vegetais microscópicos também causam problemas de ordem fitossanitária:

(3) problemas fitossanitários: eram restritos ao desenvolvimento da cultura no campo;

(4) posteriormente verificou-se que frutas, vegetais, sementes e grãos perdiam o brilho, a maciez ou a capacidade de germinar, por razões imperceptíveis ao olho humano;

(5) até que tais problemas afetaram o comércio internacional e alertaram a comunidade científica quanto a um "perigo invisível", que sob determinadas condições, causam a deterioração dos grãos e alimentos, durante o transporte ou o armazenamento. (CENTREINAR, 2004, p. 1, grifos nossos, aspas do autor)

$\mathrm{Na}$ mudança do tempo dos verbos, que passam do presente para o passado - em (1) e (2), respectivamente: "Os fungos são", "apresentam estruturas"; em (3) e (4): "eram", "verificou-se", etc. -, os enunciados (3) e (4) nos remetem a uma memória, a um lugar no passado em que o agricultor, isolado, lidava com os problemas fitossanitários que os fungos causavam sem saber a razão desses problemas, que eram "imperceptíveis ao olho humano". Ao passo que eles tomam uma dimensão mundial enunciado (5) -, à qual poderíamos associar o período em que a agricultura se torna subsidiária do desenvolvimento urbano-nacional de diversos países, com o início das exportações de grãos e outros insumos agrícolas, configurando-se um comércio internacional desses produtos, passam a afetar o comércio internacional e a chamar a atenção da "comunidade científica" para um perigo.

\footnotetext{
${ }^{6}$ Todos os trechos retirados da apostila são transcritos sem modificações. Eventuais inadequações à norma culta não serão alteradas nos enunciados citados.
}

FERREIRA - Apostila de treinamento na... 
Nesse relato feito em forma de tópicos na apostila, cujo conteúdo tentamos parafrasear, encontramos marcas de dois saberes a respeito dos problemas relacionados aos fungos dos grãos, que são da ordem do científico e da experiência prática - o saber tradicional. De (1) a (3), os termos usados para definir e caracterizar os fungos são próprios do âmbito científico: "microorganismos", "estruturas", "dimensões microscópicas", "problemas fitossanitários". Após o início do relato, que começa em (3), é trazido à cena esse saber que se restringe ao perceptível ao "olho humano", que assumimos como fruto da experiência prática no campo.

De "microorganismos", "estruturas relativamente simples" de "dimensões microscópicas", os fungos passam a ser nomeados como um "perigo invisível", como algo imperceptível ao olho humano. Antes do interesse da comunidade científica, não se sabia a razão da deterioração dos grãos e dos alimentos, pois os fungos eram "invisíveis", já que para enxergá-los seria necessário o uso de equipamento tecnológico como os microscópios.

É justamente esse jogo que se configura ao longo das apostilas de treinamento técnico entre dois saberes exteriores ao campo pedagógico e que são produzidos em outros lugares (a ciência e a experiência prática) que gostaríamos de sublinhar.

Desse modo, além de mostrarmos que no processo discursivo da apostila há a delineação de espaços de produção, modos de produção de sentido que são da ordem do científico e do tradicional, interessa-nos mostrar, principalmente, nesse jogo instaurado entre essas instâncias produtoras de saber, como se dá a tensão, a luta, a imposição de forças.

Vejamos o enunciado abaixo, retirado da apostila "Aeração de grãos":

(6) No Brasil, por ser a aeração uma técnica que está sendo aplicada há poucos anos, há uma concepção de uso do sistema como "ferramenta" para a solução de problemas de aquecimento da massa; isto é, uso da aeração como técnica corretiva. $\mathrm{Na}$ verdade, deve-se entender que a aeração é uma técnica de conservação para ser usada como maneira preventiva. (CENTREINAR, 2004, p. 1, grifos nossos, aspas do autor) 
Aqui também vemos dois saberes a respeito da aeração de grãos: um, em que é atribuído à técnica um estatuto de correção - maneira de corrigir o excesso de calor na massa de grãos -, e outro ao qual é atribuído o estatuto de prevenção - a utilização desse saber como medida preventiva. A essas atribuições correspondem, respectivamente, os saberes tradicional e científico.

Diante dos enunciados apresentados, podemos perceber na materialidade lingǘstica o jogo textualizado através de elementos como o questionamento do caráter totalmente apropriado dos termos perigo invisivel, em (5), e ferramenta, em (6), que aparecem entre aspas. Essas marcas formais que constituem relação com uma alteridade, segundo Maingueneau (1997, p. 90), "não significam colocar explicitamente que certos termos são mantidos à distância, é mantê-los à distância e, realizando este ato, simular que é legitimo farế-lo". Este é um mecanismo que se opera na apostila e que está relacionado ao conjunto do movimento da enunciação de que as aspas são vestígios: o que quer legitimar o rebaixamento de um saber que é da ordem do não-científico - daquilo que se opõe ao desejável.

No caso do enunciado (6), o termo ferramenta, apresentado entre aspas, se refere a uma "concepção", indesejada, portanto, que existe em um lugar que não é especificado. Entretanto, podemos localizar tal concepção no domínio do conhecimento tradicional a respeito da aeração. Esse indesejado deve então ser substituído pela "verdade", que é o uso da aeração como prevenção: "Na verdade, deve-se entender que a aeração é uma técnica de conservação para ser usada como maneira preventiva". No decorrer da apostila sobre aeração, vemos repetidas vezes a confirmação desta "verdade" - produzida de acordo com um certo regime, como afirma Foucault - depositada na prevenção através de enunciados como: "os benefícios que a aeração pode trazer para o produto armazenado somente serão plenamente aproveitados quando essa técnica é realizada de maneira preventiva" (CENTREINAR, 2004, p.18).

\subsection{O Olhar}

Nesse quadro de tensão entre saberes, gostaríamos de destacar de maneira especial dois níveis diferentes de análise, a partir das 
investigações empreendidas por Foucault (1963) em $O$ nascimento da clinica: o olhar e a linguagem. Passemos primeiro ao olhar.

Ao saber tradicional, como podemos ver em (4) e (5), é reservado o olhar que percorre o corpo na sua superfície, o que é perceptível "ao olho humano". Esse olhar constata um "perigo", mas é incapaz de saber a razão, já que o perigo é "invisível". A doença (os fungos), então, se define pela estrutura do visível, pela superfície: "verificou-se que frutas, vegetais, sementes e grãos perdiam o brilho, a maciez"; "causam a deterioração dos grãos e alimentos".

O olhar de superfície, de acordo com as apostilas, é incapaz de diferenciar espécies de fungos (7) e insetos (8):

\section{Aspergillus flavus e Aspergillus parasiticus}

(7) $>$ são as duas espécies de fungo que produzem as aflatoxinas;

a diferenciação das duas espécies é extremamente difícil e requer equipamentos mais sofisticados. (CENTREINAR, 2004, p. 5, grifos nossos)

(8) $>$ As três espécies, $S$. zeamais, $S$. oryzae e $S$. granarius são as mais destrutivas de cereais armazenados; [...] $S$. zeamais e $S$. oryzae não podem ser diferenciados pelas características externas. Para discerni-los é necessário o estudo da genitália. (CENTREINAR, 2004, p. 9, grifos nossos)

Nos enunciados acima, vemos que para a diferenciação das duas espécies de fungos ("Aspergillus flavus" e "Aspergillus parasiticus") e das duas espécies de insetos ( $S$. zeamais e $S$. oryzae) é necessário um outro olhar, um olhar que requer tecnologia, aparelhos para a diferenciação. Também nos artigos, a partir dos quais foram feitas as apostilas, encontramos enunciados que remetem a esse olhar que percebe $\mathrm{o}$ externo:

(9) As espécies Sitophilus oryzae e Sitophilus zeamais são, praticamente, idênticas e não podem ser diferenciadas pela parte externa do inseto. (PUZZI, 1986, p. 329, grifos nossos)

Em (8) e (9), o olhar que vê o externo não é capaz de diferenciar os insetos Sitophilus oryzae e Sitophilus zeamais, pois são "praticamente idênticos". A esse olhar é atribuída a incapacidade (8), daí a necessidade de aparelhos sofisticados (7), o alerta ao que não se enxerga (5). Dessa 
forma, vemos se esboçar na trama discursiva a atribuição estatutária do olhar em superfície relacionado ao saber tradicional àquilo que é rebaixado, desprestigiado.

Como vimos anteriormente, de acordo com Foucault (1963), na medicina clássica a doença se definia pela estrutura visível, pela superfície. O olhar de superfície do médico percorria horizontalmente o corpo doente e a doença se constituía pela estrutura do visível. Já na medicina moderna, precisamente com a fusão da clínica com a anatomia patológica (século 19), o olhar médico deve penetrar verticalmente no corpo. A medicina dos sintomas cede lugar à medicina do órgãos - Idade de Bichat: a investigação sobre os tecidos do organismo permite uma nova configuração de corpo. A doença se define pela relação com a profundidade.

Por sua vez, o olhar do saber científico sobre armazenamento que se apresenta nas apostilas e nos artigos científicos que utilizamos em nossa análise é esse que penetra verticalmente o grão, que busca suas "estruturas" (2), que não se restringe à "parte externa do inseto" que ataca os grãos - como em (8), onde a distinção só pode ser feita por características internas da genitália - e usa de tecnologias como microscópios para esse estudo, assim como o olhar clínico misturou-se com a anatomia que estuda as alterações dos tecidos, utilizou-se de instrumentos técnicos mais potentes e de pesquisas semelhantes às das causas patogênicas nas profundezas do organismo.

\subsection{A linguagem}

Foucault (1963) mostra que, com a reforma na pedagogia realizada nos hospitais, mudam-se os modos de inserção do sujeito falante. Nesse deslocamento, outras relações de sujeito são estabelecidas e emerge uma nova linguagem. A nova clínica, por um outro modo de enunciar, inventa um novo conjunto de discursos e práticas.

A partir desse estudo de Foucault, dissemos que os planos científico e tradicional possuem modos distintos de produção de enunciados em função de diferentes posições de subjetividade, de acordo com o que explicitamos no item 3. Nesse sentido, é interessante perceber, no nível da linguagem, a tensão instaurada entre os saberes científico e tradicional. 
O trecho da apostila "Pragas dos grãos armazenados e métodos de controle" mostrado em (10), é exemplar para identificarmos os dois saberes e as relações entre eles:

(10) Para designar uma espécie, dá-se um nome comum ou vulgar, mas muitas vezes este nome pode englobar várias espécies, como por exemplo, a palavra "gorgulho". Para evitar estes problemas, a cada espécie dá-se um nome científico, geralmente em latim, composto de duas palavras, a primeira correspondente ao gênero e a segunda, à espécie. Às vezes acrescenta-se uma terceira palavra, que corresponde ao nome da pessoa que o identificou. (CENTREINAR, 2004, p. 2, grifos nossos)

O enunciado (10) materializa sinteticamente a relação entre os saberes tradicional e científico no que diz respeito à nomeação. $\mathrm{O}$ nome "comum" ou "vulgar" dado às diversas pragas que atacam os grãos pertence à linguagem do saber tradicional em armazenamento. Quem realiza essa nomeação, quem dá o nome "comum" é o sujeito agricultor; é o modo de produção de enunciados do saber tradicional que é rebaixado ao comum, ao "vulgar", ao impróprio, ao que gera problemas que devem ser evitados. Estão em jogo os nomes científicos e os "populares".

Podemos dizer, a partir de Foucault (1963), que o olhar e a linguagem estão imbricados, de forma que, como mostramos nos enunciados analisados acima, manifestam juntos diferentes posições de subjetividade - do agricultor e do cientista. Assim como na passagem da medicina antiga para a clínica moderna desloca-se de um espaço de representação, superficial, para um espaço objetivo, profundo, aqui também evidenciamos deslocamentos entre duas instâncias produtoras de saber: passa-se da superfície para a profundidade, do olhar que vai da horizontalidade para a verticalidade do corpo doente; em nosso caso, o grão armazenado; passa-se da nomeação "vulgar", "popular", para a nomeação em língua latina.

Podemos perceber que antes mesmo da sobreposição do saber tradicional pelo científico - de acordo com o que discutimos antes -, ou seja, antes da negação da aeração como técnica de correção e a imposição da verdade acadêmica que deve ser entendida ("na verdade, deve-se entender que..."), há uma imposição da ordem da linguagem, da 
nomeação, desencadeada pela locução "isto é". Retifica-se, além da finalidade do procedimento de aeração, que passa de correção para prevenção, a nomeação do uso desse procedimento no âmbito do saber tradicional, que passa de "ferramenta" (para a solução de problemas de aquecimento) para "técnica corretiva": $X=$ técnica corretiva, conhecido como $Y=$ ferramenta.

Em um movimento contrário a esse, em que ao invés da negação do tradicional há a afirmação e a posse desse saber, o enunciado (11), retirado da apostila sobre aeração, e o (12), retirado da apostila sobre pragas que atacam os grãos armazenados, mostram a apropriação, realizada pelo discurso científico, da nomeação de domínio popular:

(11) Remoção de Odores da Massa de Grãos Armazenados

O odor de "grãos frescos" é uma das características intrínsicas [sic] de grãos aerados. O crescimento de fungos, a fermentação e ransificação [sic] do óleo, causam odores estranhos àqueles grãos. (CENTREINAR, 2004, p 24, grifos nossos)

(12) A Tenebrionidae é uma família muito grande, com mais de 10.000 espécies de insetos conhecidos [...]. Os adultos dessas espécies medem de 3 a $10 \mathrm{~mm}$ de comprimento, são de cor castanho-avermelhada ao preto, achatados e de lados paralelos. As larvas são ativas e bem esclerosadas. Das muitas espécies encontradas em produtos armazenados, poucas são bem adaptadas em ambientes muito secos. (CENTREINAR, 2004, p. 11 , grifos nossos)

Mais do que afirmar o saber popular, parece-nos que (11) certifica a apropriação da perífrase utilizada no saber tradicional ("grãos frescos") por meio da explicação da origem desse odor: ele é característico de grãos aerados. Podemos pensar ainda que, como em (5) e (6), as aspas aqui indicam que é legítimo manter essa nomeação à distância. Em (12), ocorre a apropriação de "esclerosadas", que, como sabemos, no sentido que está em jogo (próximo ao de que as larvas se movimentam “desordenadamente"), este termo pertence ao domínio popular e é muito encontrado na linguagem oral.

No rebaixamento do olhar em superfície, na sobreposição da nomeação considerada "vulgar", a atribuição da ignorância se estende ao saber que o agricultor possui que advém da experiência prática, o que 
desqualifica esta instância produtora de saber e contribui para o apagamento da tensão entre os saberes científico e tradicional.

\subsection{O exemplo}

É interessante neste ponto compararmos as apostilas de treinamento analisadas com o estágio intermediário que Foucault (1963) chama de "protoclínica". Nesta clínica que antecede a medicina moderna, o saber médico era ensinado por meio da prática, mas com uma função eminentemente pedagógica. Como dissemos no item 3.1, a configuração da relação do campo de saber com a prática é exclusivamente a da aplicaşão; uma verdade constituída fora do pedagógico circulava nesse plano. O enunciado (13), retirado da apostila sobre fungos, aponta para essa relação de aplicação:

(13) $>$ Aflatoxinas é o termo usado para designar um grupo de toxinas produzidas por algumas cepas de A. flavus e A. parasiticus, que por serem altamente carcinogênicas, teratogênicas e mutagênicas, quando comparadas a outros compostos químicos, têm recebido maior atenção dos pesquisadores e são as mais estudadas. (CENTREINAR, 2004, p. 7, grifos nossos)

E o enunciado (5), já mostrado anteriormente:

(5) $>$ até que tais problemas afetaram o comércio internacional e alertaram a comunidade científica quanto a um "perigo invisível" [sic], que sob determinadas condições, causam a deterioração dos grãos e alimentos, durante o transporte ou o armazenamento. (CENTREINAR, 2004, p. 1, grifos nossos)

Os enunciados acima apresentam as marcas dos sujeitos que produzem o saber científico que é objeto desse discurso pedagógico: os sujeitos "pesquisadores", em (13), ou "cientistas", em (5). O pedagógico não constitui em si uma experiência, mas o resultado de experiências, "estudos" anteriores realizados por esses sujeitos, ou, pela "comunidade científica". O pedagógico aqui é lugar de circulação desse saber científico que quer impor-se sobre o saber tradicional, "popular".

A aplicação aparece, assim, como uma maneira de apresentar conhecimentos científicos aos aprendizes de armazenamento: 
(14) $>\mathbf{O}$ reconhecimento científico da importância das micotoxinas ocorreu a partir de 1960, com a morte de 100.000 perus, e surto de doenças em frangos, suínos e bezerros em fazendas da Inglaterra.

$(15)>$ Esse episódio resultou na descoberta das aflatoxinas e iniciou a era das micotoxinas. (CENTREINAR, 2004, p. 6, grifos nossos)

Como vemos em (14) e (15), a "descoberta" é reservada ao sujeito-pesquisador, aquele que "reconhece" cientificamente a doença (micotoxinas). É ele que descobre, produz esse saber científico que é apresentado nas apostilas dos cursos de extensão rural.

Dito isso, poderíamos afirmar, a partir de nosso corpus, que na prática do apostilamento desse saber sobre o armazenamento os grãos servem para exemplificar as "doenças", aqui entendidas como fungos, micotoxinas descobertas, pragas, acidentes em unidades armazenadoras, enfim, conhecimentos produzidos fora do campo pedagógico.

Nas apostilas, fala-se dessas "doenças", dos males e cuidados a serem observados para o prolongamento da "saúde" dos grãos a partir de experiências anteriores onde a exemplificação tem outro estatuto, conforme veremos adiante - usamos o termo "saúde" porque armazenar é isto: manter ao máximo o tempo útil de consumo dos grãos, ou seja, preservar as qualidades do produto, mantê-lo saudável, pois os grãos são organismos vivos.

Comparemos os enunciados abaixo: (16) pertence ao artigo científico "Fatores de acidentes em armazenagem de grãos" e (17) pertence à apostila "Segurança do trabalho em unidades armazenadoras":

(16) Ábila Filho (1971) cita os seguintes fatores relacionados aos acidentes de trabalho:

a) agente da lesão: o que determina a lesão quando em contato com a pessoa e identifica-se pela parte do corpo onde ele se localiza (por exemplo, componente de uma máquina);

b) condição insegura: as falhas, defeitos, carência de dispositivos de segurança, e outros, os quais colocam em risco a integridade física e a saúde das pessoas (por exemplo, fios expostos e ventilação inadequada); 
c) ato inseguro: comportamento do trabalhador, seja ele consciente ou inconsciente, o qual expõe a riscos de acidentes (por exemplo, brincadeiras e uso de equipamentos inadequados). (LORINI et al., 2002, p. 215, grifos nossos).

(17) Acidentes de Trabalho

Fatores relacionados aos acidentes de trabalho:

a) agente da lesão: por exemplo, componente de uma máquina descoberto;

b) condição insegura: por exemplo, fios expostos e ventilação inadequada;

c) ato inseguro: por exemplo, brincadeiras e uso de equipamentos inadequados. (CENTREINAR, 2004, p. 2, grifos nossos)

O enunciado (17) é elaborado a partir de (16), entretanto, como podemos ver acima, há um apagamento em (17), uma mudança na forma desse enunciado a partir da qual podemos descrever os diferentes estatutos da exemplificação nesses planos de enunciação, de acordo com a análise que Foucault realiza em $O$ nascimento da clínica.

$\mathrm{O}$ autor descreve uma diferença fundamental entre os que praticam a arte de curar após a intervenção de Cabanis $^{7}$ e a reorganização do ofício médico do ano $\mathrm{XI}^{8}$ do calendário republicano Francês (1802). Na formação do oficial de saúde eram essenciais os anos de prática; já na formação do médico o ensino teórico era completado com uma experiência clínica. Essa é a diferença apontada por Foucault.

7 Segundo Foucault (1963), Cabanis tenta sobretudo formular em linhas gerais uma teoria da profissão médica. Sua proposta não foi aceita, mas indicava fundamentalmente a solução que iria ser adotada para a reorganização do ofício médico, ditando para este o estatuto de profissão liberal e protegida que conservou até o século XX.

${ }^{8}$ Em nossos cálculos, o ano XI do calendário republicano corresponde ao ano de 1802. Trata-se do calendário instituído na França pela Convenção, na Revolução Francesa, em 24/10/1793, tendo sido novamente substituído pelo calendário gregoriano em $01 / 01 / 1806$, e no qual o ano tinha 12 meses de 30 dias cada um, acrescidos de cinco dias complementares, dedicados às festas republicanas. Convencionou-se que o ano I da República teria começo em 22 de setembro de 1792. 
A mudança na forma dos enunciados em (17) ocorre em função do plano de enunciação ao qual eles passam a pertencer: o pedagógico. Nesse plano, assim como nos anos de prática exigidos do oficial de saúde, de acordo com a legislação do ano XI, a experiência é integrada no nível da percepção, da memória e da repetição, isto é, no nível do exemplo. Assim, da mesma forma que para os oficiais de saúde, ao nível do exemplo se faz a prática nas apostilas que analisamos, sendo que em (17) encontramos a forma fator de acidente X: exemplo.

No plano científico, assim como na clínica, "trata-se de uma estrutura mais sutil e complexa", em que a integração da experiência se faz nos níveis citados anteriormente, mas "em um olhar que é, ao mesmo tempo, saber" (FOUCAULT, 1963, p. 89). Essa experiência em armazenamento pode ser evidenciada em (16) sob a forma fator de acidente $X:$ saber (exemplo).

Semelhante à relação mestre-discípulo que se configurou na parte prática do ensino dos oficiais de saúde, onde havia somente a exemplificação de um saber produzido em outro lugar, nos cursos de extensão rural em armazenamento de grãos a pedagogização desse saber que envolve a "saúde" dos grãos possui apenas uma direção, a que vai de cima para baixo, do saber constituído no plano científico (experiência do armazenamento) à ignorância que é atribuída ao aprendiz-agricultor? .

\subsection{A prática}

No caso dos cursos de extensão rural em armazenamento de grãos dados pelo Centreinar, o aprendiz já possui um conhecimento em armazenamento proveniente da experiência prática no campo, esta sim realizada por um olhar que produz saber. Dessa forma, a prática

\footnotetext{
${ }^{9}$ É essa relação vertical e de uma única direção que caracterizou a dimensão educativa da Extensão Rural em seu surgimento no Brasil, no final dos anos 1940, como aponta Moreira (2004). Segundo a autora, o conhecimento "legítimo" do extensionista frente ao conhecimento "ultrapassado" do agricultor afastava qualquer possibilidade de troca entre os saberes. Era somente vencendo a resistência do agricultor em adotar novas técnicas que se poderia desenvolver a agricultura e a família rural. O agricultor, que era considerado "carente" dos conhecimentos requeridos para implementar novas formas produtivas, logo teve seus conhecimentos agrícolas desqualificados, considerados tradicionais, atrasados. Sua resistência em adotar novas tecnologias foi explicada em razão de sua ignorância e "falta de cultura" (baixa escolaridade), de seu desconhecimento e incapacidade para compreender a eficácia dessas técnicas científicas.
}

FERREIRA - Apostila de treinamento na... 
realizada nos cursos de armazenamento (que é produzida em outro lugar) e a experiência prática no campo possuem estatutos diferentes.

No enunciado (18), retirado da apostila sobre aeração de grãos, encontramos marcas da prática de cunho empirista realizada no plano científico à qual é atribuído o olhar em profundidade que se dá por meio de instrumentos tecnológicos, neste caso, instrumentos de medição:

(18) Numa massa de grãos armazenados é comumente suposto que todos os grãos foram estocados com o mesmo teor de umidade. Na prática, o produto está com teor de umidade variando em torno do valor médio. Pode-se encontrar grãos que estão de 1 a 2 pontos percentuais de umidade tanto acima quanto abaixo desse valor médio. (CENTREINAR, 2004, p. 19, grifos nossos)

Podemos dizer que em (18) "na prática" remete-nos exatamente a essa prática realizada no plano científico que é produtora de saber e se apresenta aqui como a verdade a ser percebida, memorizada e repetida. Da mesma maneira que para a prática exigida do oficial de saúde, a prática exigida do aprendiz de armazenamento através do pedagógico é um empirismo controlado: "saber fazer depois de ter visto" (FOUCAULT, 1963, p. 89).

Nesse sentido, há o embate entre duas práticas e uma tensão instaurada entre elas no apostilamento/pedagogização realizado na extensão rural: uma, que em sua aplicação supõe a ignorância do aprendiz pela exemplificação e repetição; e outra que, como no plano científico, une exemplificação e saber (plano da experiência prática em armazenamento realizada no campo).

Vejamos mais uma vez o enunciado (6):

(6) No Brasil, por ser a aeração uma técnica que está sendo aplicada a poucos anos, há uma concepção de uso do sistema como "ferramenta" para a solução de problemas de aquecimento da massa; isto é, uso da aeração como técnica corretiva. $\mathrm{Na}$ verdade, deve-se entender que a aeração é uma técnica de conservação para ser usada como maneira preventiva. (CENTREINAR, 2004, p. 1, negrito nosso, aspas do autor) 
Conforme dissemos anteriormente, para o enunciado acima podemos afirmar que ao modo de utilizar a aeração que possui o estatuto de correção corresponde o saber tradicional, popular, e ao modo de utilizar esse sistema que possui o estatuto de prevenção, corresponde o saber científico.

Além disso, é interessante notarmos neste ponto da análise a indicação da mudança no modo com o qual o agricultor usa o sistema de aeração pela imposição "da verdade" de que ele deve passar da correção para a prevenção, ou seja, deve passar de usar o sistema de aeração quando for necessário remediar para usá-lo de maneira premeditada, antecipando um possível problema de aquecimento da massa de grãos.

O que queremos dizer, para além do que já discutimos sobre o enunciado (6), é que ele indica uma mudança efetiva na prática de armazenar efetuada pelo agricultor. Parece-nos que aqui se intensifica a tensão entre uma prática realizada no plano científico e outra realizada na experiência prática do campo.

Ressaltamos que para nossa análise não importa o procedimento em si, ou qual técnica (corretiva ou preventiva) é "correta", "verdadeira", ou tem mais eficácia no armazenamento. Importa-nos o funcionamento da aplicação de uma prática que se apresenta no plano pedagógico como uma experiência que é integrada no nível da exemplificação e que quer substituir outra que, como ela, produz saber fora do pedagógico.

Correção e prevenção dizem respeito, especificamente, ao modo de utilizar o sistema de aeração durante o armazenamento, isto é, ambas as maneiras envolvem este tipo de resfriamento de grãos: força-se a movimentação do ar ambiente através da massa de grãos. E, entre os agricultores que chegam ao curso de extensão já sabendo utilizar esta técnica, a maioria a utiliza para corrigir o aquecimento dos produtos armazenados, de acordo com o que foi apresentado nas citações retiradas das apostilas de treinamento.

Com base no que discutimos sobre a tensão instaurada no plano pedagógico entre práticas que são realizadas em um olhar que "é ao mesmo tempo saber", de acordo com o que encontramos em Foucault, podemos pensar que há um movimento de dominação que indica a mudança da experiência prática de armazenamento - que se dá no âmbito de um empirismo não-controlado - para um empirismo controlado, 
reservando somente à prática empreendida no domínio científico a autorização para a produção de saber e sua legitimação. É desse modo que o pedagógico (nível do exemplo) se constitui no plano da aplicação de uma prática produzida no científico.

A essa mudança corresponde, exatamente, o predomínio do discurso científico que circula na apostila sobre o modo de produção de saber na experiência prática. Nesse momento, quando o agricultor muda a sua prática - como vimos, aqueles que usam a aeração de forma corretiva, passam a usá-la de forma preventiva - pela repetição e memorização da experiência prática do campo científico, a tensão é então dissipada: o agricultor utiliza esse saber científico para armazenar.

\section{CONSIDERAÇÕES FINAIS}

Ao voltar nosso olhar para o instrumental apostila de treinamento do plano pedagógico na extensão rural em armazenamento de grãos, observamos que na circulação do saber do científico para a aplicação se configura uma tensão entre duas instâncias produtoras de saber: a experiência prática do âmbito científico e a experiência prática do campo.

A partir das investigações de Foucault em $O$ nascimento da clínica, optamos por dividir a análise em quatro partes que dizem respeito a diferentes níveis de análise: o olhar, a linguagem, o exemplo e a prática.

No primeiro deles, o olhar, observamos que de maneira semelhante à medicina clássica, onde o médico percorria horizontalmente o corpo doente e a doença se constituía pela estrutura do visível, vemos se esboçar na trama discursiva a atribuição, ao saber tradicional, do olhar de superfície que é incapaz, desprestigiado. Já para o saber científico, é atribuído o olhar em profundidade, que penetra o grão e suas doenças (fungos e pragas) e busca suas estruturas, de maneira análoga à fusão da clínica com a anatomia patológica, em que o olhar médico deve penetrar verticalmente no corpo e a doença se definir pela relação com a profundidade. Dessa forma, se configura no plano do dizer uma tensão entre olhares que são da ordem do científico e da experiência prática campestre. E ao compararmos as apostilas aos artigos científicos que compõem nosso corpus, também encontramos as atribuições descritas 
acima, bem como a imposição do olhar em profundidade e a incapacidade conferida ao olhar em superfície.

O olhar e a linguagem, segundo Foucault, estão imbricados e manifestam juntos diferentes posições de subjetividade, em nosso caso: do agricultor e do cientista. Nesse sentido, afirmamos, com base na análise efetuada no corpus no nível da linguagem, que o olhar em superfície atribuído ao sujeito agricultor/armazenador é associado à linguagem "vulgar", comum, depreciada, e que é sujeita ao erro. Mais do isso, é o modo de produção de enunciados da experiência prática no campo que é negado. E o olhar em profundidade do sujeito cientista é associado à linguagem não-popular, à nomeação "científica", não suscetível de erro, prestigiada, e que se impõe, mesmo que em alguns casos seja pela legitimação da apropriação da nomeação pertencente ao domínio popular. Lembramos que na comparação das apostilas com os artigos científicos a partir dos quais elas foram elaboradas também encontramos nestes essa relação de imposição que se dá por meio da sobreposição da nomeação popular pela científica.

Podemos dizer que a experiência em armazenamento ocorre no plano científico e na prática rural, pois em ambos a integração da prática envolve a exemplificação e a produção de saber. Contudo, no plano pedagógico das apostilas de treinamento, assim como na prática exigida dos oficiais de saúde, como relata Foucault, a experiência científica de armazenamento é integrada no nível da percepção, da memória e da repetição, isto é, somente no nível do exemplo. Em outras palavras, a aplicação de saberes científicos produzidos fora do domínio pedagógico tem a ver somente com a exemplificação desses e, por isso, não constitui em si uma experiência, como a experiência clínica após a reforma da pedagogia realizada nos hospitais. Nesse quadro de aplicação, estabelecese uma relação semelhante à de mestre-discípulo encontrada no ensino dos oficiais de saúde, de acordo com a legislação do ano XI (1802): a exemplificação de um saber produzido na academia - em nosso caso, o armazenamento de grãos - possui apenas uma direção, a que vai de cima para baixo, do saber constituído no plano científico (experiência do armazenamento) à ignorância que é atribuída ao aprendiz da extensão rural.

Assim, configura-se uma tensão no plano pedagógico entre a experiência prática agrícola - os aprendizes chegam à extensão rural já 
sabendo armazenar -, e a experiência prática científica, ambas produtoras de saber. Os enunciados das apostilas que mostram a indicação da mudança na prática de armazenar efetuada pelo agricultor sinalizam um movimento de dominação de um empirismo controlado. Quando, de fato, o agricultor muda seu modo de armazenar, há o predomínio do discurso científico sobre o modo de produção de saber na experiência prática - que se dá por um empirismo não-controlado. Desse modo, somente à prática empreendida no âmbito científico é reservada a produção de saber, e o pedagógico constitui o plano da aplicação de uma prática produzida no domínio científico. A tensão formada entre os saberes tradicional e científico é apagada quando o extensionista utiliza o saber científico para armazenar: sua prática é então a exemplificação de uma prática outra, científica. E ele o faz pelo pedagógico, que por sua vez se vale do instrumental apostila de treinamento.

De acordo com a análise que empreendemos, na ligação dos níveis o olhar, a linguagem, o exemplo e a prática, afirmamos que se sustenta nossa hipótese inicial de análise: a apostila funciona como uma modalidade de enunciação do saber científico que é praticado no plano da aplicação, de maneira que a prática no campo realizada pelo armazenador passa a ter o mesmo estatuto da prática científica realizada na extensão rural no que diz respeito às relações do sujeito que enuncia, isto é, aos modos de inserção do sujeito, que passa de produtor para exemplificador de saber.

\section{REFERÊNCIAS}

CENTREINAR. Curso de armazenamento, secagem e aeração de grãos. Viçosa, MG, 2004. mimeo.

FERREIRA, E.D. O discurso da ciência e o de sua aplicação: um estudo sobre a apostila de treinamento na Extensão Rural. Dissertação (Mestrado) Florianópolis, UFSC, 2007.

FOUCAULT, M. A hermenêutica do sujeito. São Paulo: Martins Fontes, 2004.

L’archéologie du savoir. Paris: Gallimard, 1969. 

Puf, 1963.

Naissance de la clinique: une archéologie du regard médical. Paris:

LORINI, I; MIIKE, L.H; SCUSSEL, V.M (Orgs.). Armazenagem de grãos. Campinas: IBG, 2002.

MAINGUENEAU, D. Novas tendências em análise do discurso. Tradução de Freda Indursky. Campinas: Pontes, 1997.

MOREIRA, J. A prática educativa da Extensão Rural construindo a agroecologia: a relação entre os saberes tradicional e moderno. In:

SEMINÁRIO Internacional Michel Foucault: Perspectivas, 2004, p. 14981506.

PUZZI, D. Abastecimento e armazenagem de grãos. Campinas: Instituto Campineiro de Ensino Agrícola, 1986.

Recebido em 26/06/07. Aprovado em 08/01/08.

Title: Collected course readings in rural extension: a space of tension between the discourse of applied sciences and the empirical rural experience

Author: Eric Duarte Ferreira

Abstract: The aim of this study is to analyse the interplay between the production and application of knowledge in a corpus composed of collected course readings used in Rural Extension training courses on grain storage. The study departs from the following question: How is scientific knowledge displaced and put into pedagogical use? In terms of methodology, we take these two fields as two levels that include distinct ways of producing utterances, according to Foucault's ideas on enunciative modalities. We believe that there is tension at the pedagogical level (the level of saying) between the scientific knowledge practiced out of the domain of science (in rural extension), and knowledge seen as "traditional" in terms of grain storage. The results indicate that the instrument 'collected course readings' works a further enunciative modality of scientific knowledge which erases the tension between 'traditional' and scientific modes of knowledge production.

Keywords: enunciative modality; knowledge circulation; discourse; collected course readings.

Titre: Manuel d'apprentissage dans l'accroissement rural: espace de tension entre le discours de la mise en pratique de la science et celui de l'expérience dans les champs Auteur: Eric Duarte Ferreira

Résumé: L'objectif de ce travail est celui d'analyser le jeu entre la production et la mise en pratique du savoir dans un corpus composé par des manuels d'apprentissage employés dans des cours d'Extension Rurale sur l'emmagasinement de grains. On est partis de la question centrale suivante: comment un savoir du domaine scientifique est

FERREIRA - Apostila de treinamento na... 
déplacé vers le domaine de l'emploi (pédagogique)? Méthodiquement, nous prenons ces domaines comme deux plans qui contiennent des moyens distincts de production d'énoncés, selon ce que Foucault (1969, 1963) développe à propos des modalités énonciatives. Nous croyons qu'il s'établit une tension dans le plan pédagogique (plan du dire) parmi les connaissances dites «traditionnelles » dans l'emmagasinement de grains. Les résultats signalent que l'instrument dit manuel d'apprentissage marche comme une autre modalité d'énonciation du savoir scientifique qui éteint la tension entre les moyens de production du savoir scientifique et «traditionnel».

Mots-clés: modalité énonciative; circulation du savoir; discours; manuel.

Título: Apostilla de entrenamiento en la extensión rural: espacio de tensión entre el discurso de la aplicación de la ciencia y el de la experiencia práctica en el campo

Autor: Eric Duarte Ferreira

Resumen: El objetivo de este trabajo es analizar el juego entre la producción y la aplicación de saber en un corpus compuesto por apostillas de entrenamiento utilizadas en cursos de Extensión Rural sobre almacenamiento de granos. Partimos de la siguiente cuestión central: ¿Cómo un saber del campo científico es desplazado para el campo de la utilización (pedagógico)? Metodológicamente, tomamos esos campos como dos planos que comportan modos distintos de producción de enunciados, de acuerdo con lo que Foucault $(1969,1963)$ desarrolla al respecto de las modalidades enunciativas. Creemos que se configura una tensión en el plano pedagógico (plano del decir) entre los conocimientos científicos practicados fuera del dominio de la ciencia (en la Extensión Rural) y los conocimientos dichos "tradicionales" en almacenamiento de granos. Los resultados apuntan que el instrumento apostilla de entrenamiento funciona como otra modalidad de enunciación del saber científico que apaga la tensión entre los modos de producción de saber científico y "tradicional".

Palabras-clave: modalidad enunciativa; circulación de saber; discurso; apostilla. 